\title{
Comparison of two interferon gamma release assays in the diagnosis of Mycobacterium tuberculosis infection and disease in The Gambia
}

\author{
Ifedayo MO Adetifa*, Moses D Lugos, Abdulrahman Hammond, \\ David Jeffries, Simon Donkor, Richard A Adegbola and Philip C Hill
}

Address: Bacterial Diseases Programme, Medical Research Council Laboratories, Fajara, The Gambia

Email: Ifedayo MO Adetifa* - iadetifa@mrc.gm; Moses D Lugos - mlugos2003@yahoo.com; Abdulrahman Hammond - ahammond@mrc.gm; David Jeffries - djeffries@mrc.gm; Simon Donkor - sdonkor@mrc.gm; Richard A Adegbola - radegbola@mrc.gm; Philip C Hill - phill@mrc.gm

* Corresponding author

Published: 25 October 2007

BMC Infectious Diseases 2007, 7:122 doi:10.1186/1471-2334-7-122

This article is available from: http://www.biomedcentral.com/I47I-2334/7/I22

(C) 2007 Adetifa et al; licensee BioMed Central Ltd.

This is an Open Access article distributed under the terms of the Creative Commons Attribution License (http://creativecommons.org/licenses/by/2.0), which permits unrestricted use, distribution, and reproduction in any medium, provided the original work is properly cited.
Received: 30 May 2007

Accepted: 25 October 2007

\begin{abstract}
Background: IFN- $\gamma$ Release Assays (IGRAs) have been licensed for the diagnosis of latent Mycobacterium tuberculosis infection (LTBI). Their performance may depend on assay format and may vary across populations and settings. We compared the diagnostic performance of an in-house $T$-cell and commercial whole blood-based IGRAs for the diagnosis of LTBI and TB disease in The Gambia.

Methods: Newly diagnosed sputum smear positive cases and their household contacts were recruited. Cases and contacts were bled for IGRA and contacts had a Mantoux skin test. We assessed agreement and discordance between the tests and categorized a contact's level of $M$. tuberculosis exposure according to where s/he slept relative to a case: the same room, same house or a different house. We assessed the relationship between exposure and test results by multiple logistic regression.

Results: In 80 newly diagnosed TB cases, the sensitivity of ELISPOT was $78.7 \%$ and for QFT-GIT was $64.0 \%(p=0.047)$. Of 194 household contacts $57.1 \%$ and $58.8 \%$ were positive for ELISPOT and QFT-GIT respectively. The overall agreement between both IGRAs for LTBI in contacts was $71.4 \%$ and there was no significant discordance $(p=0.29)$. There was significant discordance between the IGRAs and TST. Neither IGRA nor TST had evidence of false positive results because of Bacille Calmette Guérin (BCG) vaccination. However, agreement between QFT-GIT and TST as well as discordance between both IGRAs and TST were associated with BCG vaccination. Both IGRAs responded to the $M$. tuberculosis exposure gradient and were positively associated with increasing TST induration ( $p=0.003$ for ELISPOT and $p=0.001$ for QFT-GIT).

Conclusion: The ELISPOT test is more sensitive than the QFT-GIT for diagnosing TB disease. The two tests perform similarly in the diagnosis of LTBI in TB contacts. Significant discordance between the two IGRAs and between each and the TST remain largely unexplained.
\end{abstract}




\section{Background}

An estimated one third of the world's population is infected with Mycobacterium tuberculosis [1]. Interventions against latent $M$. tuberculosis infection (LTBI) may have a key role in controlling the epidemic [2]. Until recently, the identification of persons with LTBI was only possible using the tuberculin skin test (TST). However, the TST is subject to confounding by prior Bacille Calmette Guérin (BCG) vaccination in certain settings, boosting, reader variability, and false negative results in immunosuppressed persons in particular [3-5].

T-cell interferon gamma (IFN- $\gamma$ ) release assays (IGRAs) are now licensed for the diagnosis of LTBI [6-8]. They measure IFN- $\gamma$ production by sensitized T-cells in response to stimulation by relatively specific $M$. tuberculosis antigens. IGRAs differ from each other mainly with respect to the technique of IFN- $\gamma$ detection (enzyme linked immunospot; ELISPOT vs. enzyme linked immunosorbent assay; ELISA) and the samples utilized (peripheral blood mononuclear cells vs. whole blood). QuantiFERON-TB Gold intube (QFT-GIT, Cellestis Limited, Carnegie, Australia) has some advantages over ELISPOT: samples can be stored and run in batches, require less investment in equipment, and the assay is technically easier to perform. QFT-GIT uses overlapping peptides of ESAT-6, CFP-10, and TB 7.7 (from Rv2654) antigens. Antigenic stimulation occurs within the tube used to collect the blood sample.

The performance of IGRAs may vary across populations, in relation to background disease prevalence, prevalence of HIV infection, malnutrition, BCG vaccination, exposure to non-tuberculous mycobacteria and other factors [6-8]. In this study we compared the diagnostic performance of an ex vivo ELISPOT and the QFT-GIT for the diagnosis of LTBI and disease in a TB-endemic tropical setting.

\section{Methods \\ Participants}

As part of an ongoing case contact study, index cases $\geq 15$ years old with pulmonary tuberculosis (PTB) were recruited between September 2004 and February 2006, from the major government health centre of the Greater Banjul area and the Medical Research Council Laboratories outpatients' clinic. Included cases had two sputum samples positive for acid-fast bacilli by Ziehl-Neelson stain and $M$. tuberculosis on culture. After appropriate counselling, they had blood sampled for HIV test and for IGRAs.

Household contacts were visited, invited to give informed consent and interviewed. They were included if they were $\geq 15$ years of age (the age restriction of the overarching study) and lived the majority of the time on the same compound as a case. They were not eligible if treated for
$\mathrm{TB}$ in the past year and were excluded if diagnosed with $\mathrm{TB}$ within 1 month of recruitment. Contacts underwent a PPD skin test (2 TU, PPD RT23, Statens Serum Institut, Copenhagen, Denmark) using the Mantoux technique and induration was recorded at $48-72$ hours. Those with a positive skin test (mean induration diameter $\geq 10 \mathrm{~mm}$ ) were offered a chest X-ray and those with symptoms underwent a clinical assessment. Those with TB disease were referred to the National TB Control Programme for free treatment. There is no current practice of preventive treatment in The Gambia.

Four weeks after having a Mantoux test, household contacts that were selected for this comparison had samples taken for ELISPOT assay, QuantiFERON-TB Gold In-Tube (QFT-GIT) assay and HIV test. The overarching case contact study has, as per protocol, blood sampling 1 month after skin test. Contacts were selected for IGRA testing using an even consecutive balanced sampling frame that allowed for the possibility that more individuals who were skin test positive might choose to take part than those who were skin test negative. Fresh samples from all participants were processed onsite.

The study was approved by the joint Gambia Government/MRC Ethics Committee.

\section{Laboratory procedures}

Sputum smears were prepared and stained with auraminephenol[9] and confirmed by Ziehl-Neelson (Z-N). Decontaminated specimens were inoculated into one slope each of Lowenstein-Jensen medium (L-J) containing glycerol and sodium pyruvate respectively and one vial of BACTEC $9000 \mathrm{MB}$ media for isolation of M. tuberculosis. All mycobacterial cultures were identified and confirmed using standard procedures as described previously [10].

The ex-vivo ELISPOT assays for IFN- $\gamma$ were performed as previously described [11]. For this study, synthetic, sequential peptides spanning the length of ESAT- 6 and CFP-10 (ABC, Imperial College, London, UK) were used. Each peptide was 15 amino acids long and overlapped its adjacent peptide by 10 residues. ESAT- 6 and CFP-10 peptide pools were used at $5 \mu \mathrm{g} / \mathrm{ml}$. The positive control was Phytohaemaglutinin (PHA $5 \mu \mathrm{g} / \mathrm{ml}$; Sigma-Aldrich, UK). All antigens were tested in duplicate wells. Assays were counted with an automated ELISPOT reader (AID-GmbH, Strasberg, Germany). The spot forming unit (SFU) numbers counted in each well were automatically entered into a database. Supplementary details were added by double data entry. Positive test wells were pre-defined as containing at least $8 \mathrm{SFUs} /$ well $/ 2 \times 10^{5} \mathrm{PBMCs}$ more than negative control wells [12]. For a positive ESAT-6/CFP-10 result it was necessary for one or more pools of overlapping peptides to be positive. PHA wells were set to at least 
150 SFUs/well/2 $\times 10^{5}$ PBMCs above negative control wells. Negative control wells were required to have less than 20 SFUs/well $/ 2 \times 10^{5}$ PBMCs [12]. The ELISPOT was considered to have failed if the specifications for the negative control and PHA wells were not met.

The QuantiFERON ${ }^{\circledR}$-TB Gold In-Tube (QFT-GIT) assay was carried out according to the manufacturer's instructions[13] In the first step of this test, $1 \mathrm{ml}$ of whole blood was collected directly into $2 \times 1 \mathrm{ml}$ blood collection tubes containing either TB-specific antigens (ESAT-6, CFP-10, and TB7.7) or nil (negative control). They were incubated at $37^{\circ} \mathrm{C}$ for 16 to $24 \mathrm{~h}$ before plasma was harvested and stored at $-20^{\circ} \mathrm{C}$ until determination of IFN- $\gamma$ levels by QFT-GIT ELISA using a recombinant human IFN- $\gamma$ standard. The IFN- $\gamma$ levels were measured in international units (IU) with a Dynex ImmunoAssay System ELISA reader version 6.0 (Dynex Technologies, West Sussex, UK). The raw data were entered into QFT-GIT analysis software. A positive result was defined as IFN-g concentration in antigen stimulated tube minus that in the negative control tube $\geq 0.35 \mathrm{IU} / \mathrm{mL}$. There was no positive control tube.

Testing for HIV-1 or HIV-2 infection was by competitive enzyme linked immunosorbent assays (Wellcome Laboratories, Kent, UK) and Western blot (Diagnostics Pasteur, Marnes-la-Coquette, France).

\section{Ascertainment of exposure}

$\mathrm{TB}$ contacts were categorized according to where they slept: in the same bedroom as the index case, a different bedroom in the same house, or in a different house in the same compound [14,15].

\section{Data management and analysis}

All data were entered using double data entry into an ACCESS database and checked for errors. The concordance between the ELISPOT, QFT-GIT and TST was assessed by calculation of a kappa statistic and discordance by McNemar's test. A random effects logistic regression model, taking into account household clustering, was used to assess the relationship between sleeping proximity to an index case and test results. Age and sex were included in the analysis at the outset. Other variables assessed for inclusion in the model were ethnicity, BCG scar status, smear grade and duration of cough of the respective index case. The likelihood ratio test was used to test for trend and for interaction between variables. All statistical analyses were conducted using Stata software (version 9; Stata Corp, College Station, TX).

\section{Results}

Three hundred and twenty individuals were recruited for the overarching study, 194 household contacts and $80 \mathrm{~TB}$ cases were selected for this comparison study. Just over
$60 \%$ of the household contacts were female while $60 \%$ of cases were male. Only 10 (3.7\%) of those tested overall were HIV positive (Table 1). One hundred and eightyseven (96.4\%) had chest X-rays done at recruitment: six (3.6\%) had some radiological abnormalities present. All 6 were asymptomatic. One had been treated for TB in the past; and 2 were diagnosed with TB disease over the next few months. The results for the 2 cases were not included in those for the $80 \mathrm{~TB}$ cases that were sampled at recruitment.

All 80 smear positive TB index cases had both ELISPOT and QFT-GIT tests performed. Figure 1 shows the distribution of the IGRA results in index cases. None of the QFTGIT tests in cases failed; while there were 5 (6.25\%) failed ELISPOT tests (positive control criteria not met). Of the 75 cases that had both ELISPOT and QFT-GIT results, 59 (78.7\%; 95\% CI: 67.7-87.2\%) cases had a positive ELISPOT while 48 (64.0\%, 95\%CI: 51-73\%) were positive by QFT-GIT. This difference in sensitivity was statistically significant ( $\mathrm{p}=0.047)$. While there was significant discordance (McNemar's test: $\mathrm{p}=0.02$ ) between the two tests as shown in figure 1, the overall agreement in TB cases was $69.3 \%$ (concordance, $\kappa=0.27$ ).

Valid ELISPOT and QFT-GIT results were available for 182 and 187 contacts respectively. The difference in the proportion of failed tests was not significant $(\mathrm{p}=0.24)$. The 7 QFT-GIT results excluded all failed the criteria for negative controls as well as $5(42 \%)$ of the excluded 12 ELISPOT results - the other 7 (58.3\%) did not meet the criteria for the positive control. Overall, 104 (57.1\%) of 182 contacts tested positive to the ELISPOT (95\% CI, 49.9\%$64.4 \%)$ and $110(58.8 \%)$ of 187 were QFT-GIT positive (95\% CI, 51.7\%-65.9\%). A total of 175 had both ELISPOT and QFT-GIT results. Twenty-six (25.5\%) QFT-GIT positive contacts were ELISPOT negative while 24 (24\%) ELISPOT positive contacts were QFT-GIT negative. The overall agreement between the two tests was $71.4 \%(\kappa=$ $0.41 ; 95 \% \mathrm{CI}, 0.27-0.56)$ and there was no significant discordance $(\mathrm{p}=0.29)$.

Figure 2 shows the distribution of IGRA results by TST in household contacts. Just under half were skin test positive (48.6\%). Twenty-three (27.3\%) TST positive contacts were ELISPOT negative and 38 (42.2\%) ELISPOT positive contacts were TST negative. The overall agreement between the ELISPOT test and TST was $65 \%(\kappa=0.31$; 95\% CI: $0.16-0.44$, discordance, $\mathrm{p}=0.055)$. Sixteen (18.8\%) TST positive contacts were QFT-GIT negative and 33 (36.2\%) QFT-GIT positive contacts were TST negative. The overall agreement between QFT-GIT and TST was $71.1 \%(\kappa=0.43 ; 95 \% \mathrm{CI}, 0.29-0.57)$ and there was significant discordance $(\mathrm{p}=0.007)$. 
Table I: Characteristics of study population

\begin{tabular}{|c|c|c|c|c|c|}
\hline \multirow[t]{2}{*}{ Characteristics } & \multicolumn{3}{|c|}{$\begin{array}{c}\text { Contacts } \\
\text { Sleeping proximity gradient }\end{array}$} & \multirow{2}{*}{$\begin{array}{l}\text { Cases } \\
\mathrm{n}=80\end{array}$} & \multirow{2}{*}{$\begin{array}{c}\text { ALL } \\
n=274\end{array}$} \\
\hline & $\begin{array}{l}\text { Separate house } \\
n=38\end{array}$ & $\begin{array}{c}\text { Separate room } \\
n=115\end{array}$ & $\begin{array}{l}\text { Same room } \\
\qquad n=41\end{array}$ & & \\
\hline \multicolumn{6}{|l|}{ Age, years } \\
\hline Mean & 29.7 & 30.0 & 34.3 & 31.2 & 31.0 \\
\hline Median (IQR) & $26.5(19-36)$ & $25.0(18-36)$ & $32.0(25-44)$ & $30(23-36)$ & $28(20-37)$ \\
\hline \multicolumn{6}{|l|}{ Sex } \\
\hline Male & 18(47.4) & $38(33.1)$ & $20(48.8)$ & $5 I(63.8)$ & $127(46.4)$ \\
\hline Female & $20(52.6)$ & $77(66.9)$ & $2 \mid(5 \mid .2)$ & $29(36.2)$ & $147(53.6)$ \\
\hline \multicolumn{6}{|l|}{ Ethnic group } \\
\hline Madinka & II(28.9) & $47(40.9)$ & $\mid 7(4 \mid .5)$ & $26(32.5)$ & $101(36.9)$ \\
\hline Jola & $7(18.4)$ & $32(27.8)$ & $7(17.0)$ & $19(23.8)$ & $65(23.7)$ \\
\hline Wollof & $2(5.3)$ & $10(8.7)$ & $5(12.2)$ & $8(10.0)$ & $25(9.1)$ \\
\hline Fula & $8(21.1)$ & $7(6.1)^{\prime}$ & $4(9.8)$ & $11(13.7)$ & $30(11.0)$ \\
\hline Others & $10(26.3)$ & $19(16.5)$ & $8(19.5)$ & $16(20.0)$ & $53(19.3)$ \\
\hline \multicolumn{6}{|l|}{ Clinical Findings } \\
\hline \multicolumn{6}{|l|}{ BCG scar } \\
\hline Absent & $20(55.6)$ & $48(43.6)$ & $24(66.7)$ & $34(42.5)$ & $126(46.0)$ \\
\hline Present & 16(44.4) & $59(53.7)$ & $9(25.0)$ & $19(23.8)$ & $103(37.6)$ \\
\hline Uncertain & $0(0.0)$ & $3(2.7)$ & $3(8.3)$ & $27(33.7)$ & $45(16.4)$ \\
\hline \multicolumn{6}{|l|}{ HIV results* } \\
\hline Positive & $0(0.0)$ & $3(2.6)$ & $0(0.0)$ & $7(8.8)$ & $10(3.7)$ \\
\hline
\end{tabular}

Data are no. (\%) of persons unless stated otherwise.

BCG, Bacille Calmette-Guérin

*Data are for 178 contacts and 77 cases.

A BCG scar was clearly visible in 84 (43.3\%) household contacts. The univariate odds of a positive ELISPOT or QFT-GIT test in those BCG scar positive compared to those without scars was $1.23[0.63-2.4 ; \mathrm{p}=0.54]$ and 0.92 [0.41-2.1; $\mathrm{p}=0.84]$ respectively, both remaining non-significant after adjustment for possible confounding variables. The agreement between ELISPOT and TST did not differ significantly according to BCG scar status being $69.6 \%$ ( $\kappa=0.38 ; 95 \% \mathrm{CI}: 0.16-0.60$, discordance $\mathrm{p}=0.4$ ) in those contacts with a BCG scar and $62.4 \%(\kappa=0.26$; 95\% CI: 0.06-0.47, discordance $\mathrm{p}=0.03$ ) in those without a BCG scar. In contrast, agreement between QFT-GIT and TST was significantly different by BCG scar status ( $\mathrm{p}=$ $0.03)$, being $76.5 \%$, $(\kappa=0.52 ; 95 \% \mathrm{CI}: 0.31-0.73$, discordance $\mathrm{p}=0.11)$ in those with a scar and $68.2 \%(\kappa=$ 0.37 ; $95 \% \mathrm{CI}$ : $0.17-0.58$, discordance $\mathrm{p}=0.02$ ) in those without a scar.

In contacts, when a positive TST was defined as $\geq 5 \mathrm{~mm}$, 86 (81.1\%; 95\%CI: 73.7-88.6\%) of 106 TST positives were also QFT-GIT positive compared to 73 (71.4\%; $95 \% \mathrm{CI}$ : $62.8-80.3 \%$ ) of 102 for the ELISPOT but this difference in proportions was not significant $(\mathrm{p}=0.10)$. With a positive TST defined as $\geq 10 \mathrm{~mm}, 73$ (81.1\%; 95\%CI: 73.0-89.2\%) of 90 were QFT-GIT positive and 72 (72.7\%; 95\%CI: $63.4-82.0 \%$ ) of 88 had positive ELISPOTs. When a definition of $\geq 15 \mathrm{~mm}$ was used, 36 (78.3\%; 95\%CI: 66.3$90.2 \%$ ) of 46 had positive QFT-GIT, similar to the ELIS-
POT with 37 (78.7\%; 95\%CI: 67.0-90.4\%) of 47. These differences in proportions were also not significant $(\mathrm{p}=$ 0.18 and $p=0.96$ respectively). Figure 3 shows the proportions of contacts positive by ELISPOT and QFT-GIT across respective TST categories. There was an association between both ELISPOT and QFT-GIT results and TST categories $\left(\chi^{2}=21.6, \mathrm{p}<0.001\right.$ and $\chi^{2}=50.6, \mathrm{p}<0.001$ respectively). With increasing TST induration there was a trend towards increase in the proportions of contacts with positive ELISPOT and QFT-GIT results and this was statistically significant $(\mathrm{p}=0.003$ and $\mathrm{p}=0.0001$ respectively).

The odds of test positivity were also not related to sputum smear grade $(\mathrm{OR}=0.8[0.3-1.4]$ for ELISPOT; QFT-GIT $\mathrm{OR}=0.5[0.1-1.6)$, or duration of cough (OR, $1.0[0.9-$ 1.1] for both tests). The univariate odds of a positive result across the M. tuberculosis exposure categories (represented as sleeping proximity to a case) are shown in Table 2 . While neither showed as dramatic a change in positivity across the exposure gradient as the skin test, both IGRA tests responded significantly to increasing exposure to an index case as shown in table 2. However, significance was lost for both tests after adjusting for age, sex and ethnicity.

\section{Discussion}

This study now provides a comparison of an ELISPOT test with QFT-GIT for the diagnosis of M. tuberculosis infection and disease in a resource poor TB-endemic tropical set- 


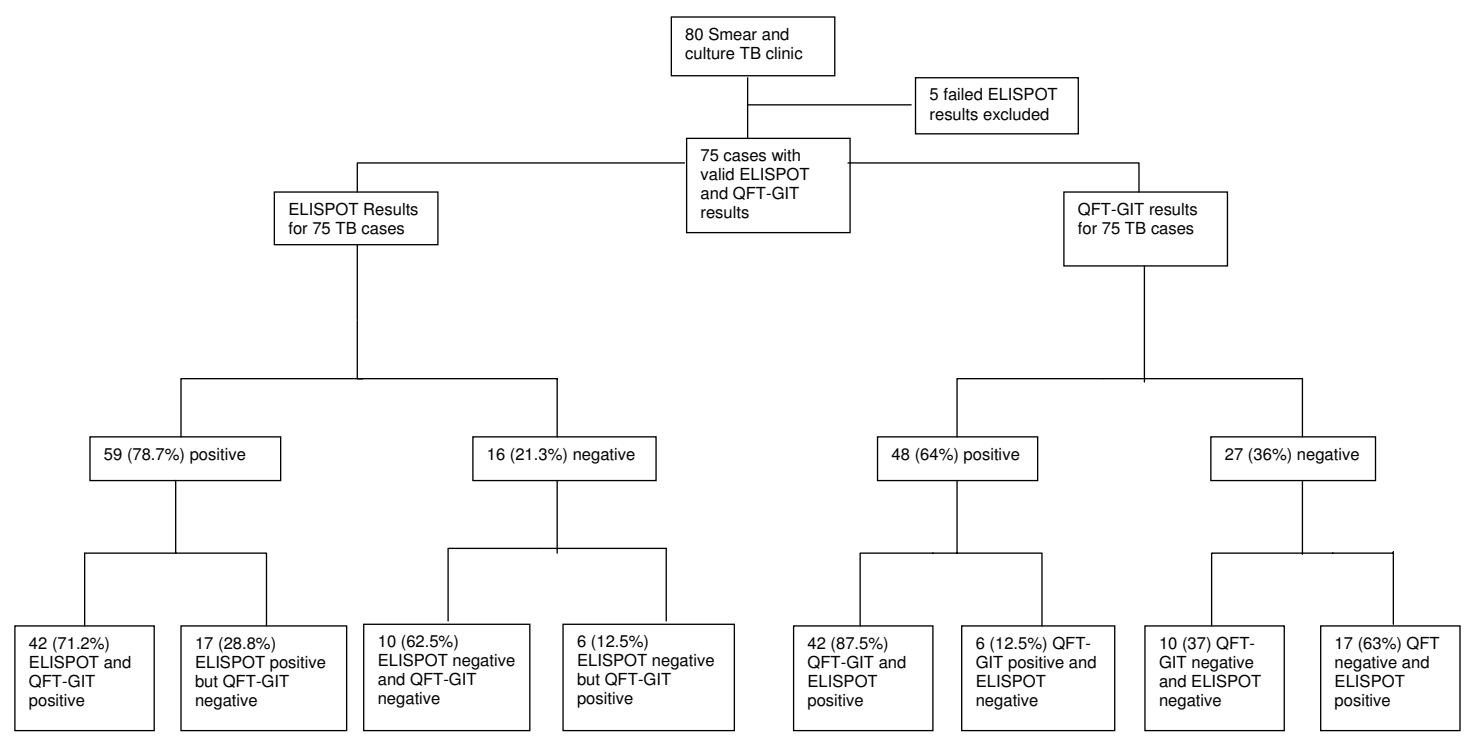

Figure I

Distribution of ELISPOT and QFT-GIT results in TB cases.

ting. Our results suggest both IGRAs, the QFT-GIT and our in house ELISPOT perform similarly in the diagnosis LTBI in contacts after recent exposure to a known TB case. However, the ELISPOT is more sensitive in diagnosing active $\mathrm{PTB}$ in cases.

The sensitivity of $78.7 \%$ for the ELISPOT is within our previously published range $72.6-89.8 \%$ [16] and $77-97 \%$ reported elsewhere in literature [7]. Estimates of 55-88\% have been obtained from studies of QFT-GIT among individuals with active $\mathrm{TB}$ - our figure of $64.0 \%$ is within this reported range [17-23]. There are other reports of comparable sensitivity for both IGRA test formats in cases $[24,25]$. It is possible that the lack of a positive control tube for QFT-GIT has led to false negative results. The

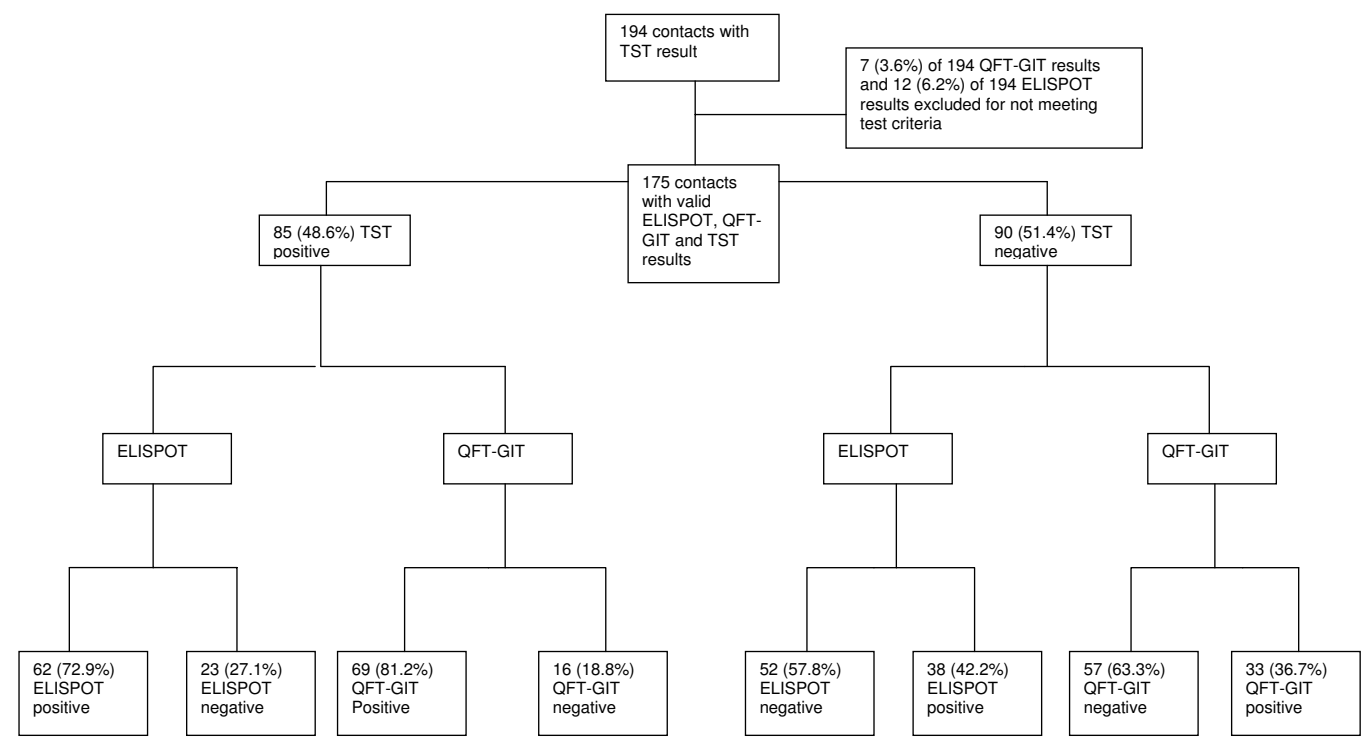

Figure 2

Distribution of ELISPOT, QFT-GIT and TST results in household contacts. 


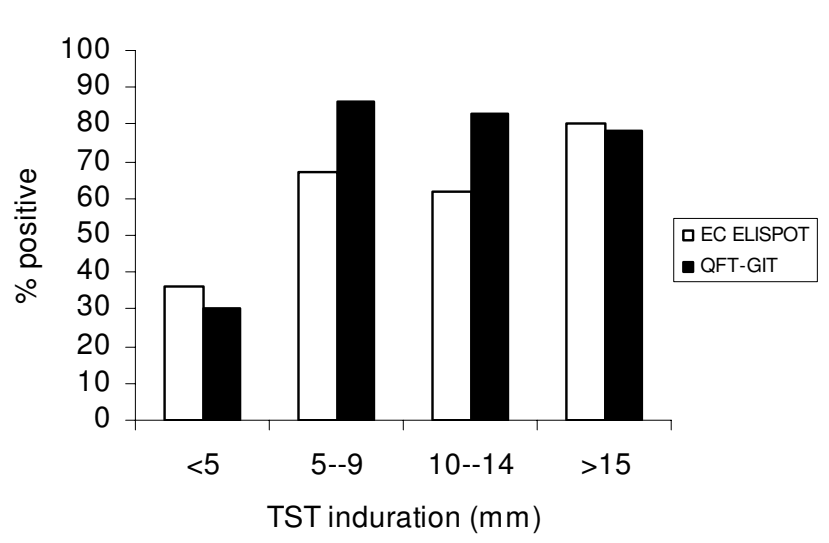

Figure 3

Proportion of positive EC ELISPOT and QFT-GIT across TST categories.

manufacturers have since introduced a positive control tube which we now use in our new QFT studies.

This study has taken advantage of a reproducible gradient of exposure to $M$. tuberculosis in The Gambia. Both tests responded appropriately to a gradient of recent exposure to $M$. tuberculosis and there was no significant divergence in results according to level of exposure. While we do not find strong evidence for sensitivity difference in case contacts, the tentative consensus from published literature is that ELISPOT does have better sensitivity with respect to LTBI [7].

Consistent with other studies, we show considerable discordance between the TST and the IGRAs and between the IGRAs themselves. Our results show significant discordance between the IGRAs in cases. Although about a quarter of ELISPOT or QFT-GIT positive contacts were negative with the other test, the discordance was not statistically significant. Discordance between IGRAs in cases and contacts has been described in several reports $[18,21,26]$. Similar to our results, more of the reported discordance is due to QFT-GIT negative and ELISPOT positive combinations. Some discordance may be related to test formats and inclusion of an additional antigen in QFT, but unfortunately remains poorly understood. Reported discordance between each IGRA and the TST ranges from 10$40 \%$ and is most often due to negative TST and positive IGRA results [6,7]. Discordance between IGRAs and TST has been related to BCG vaccination, [27-29] and to superior specificity of the IGRAs, at least in certain settings[15]. More recently, different rates of test conversion and reversion over time have been noted [30,31].

The absence of any significant effect of BCG vaccine on the TST, ELISPOT and QFT-GIT has remained a constant feature in Gambian studies, [15,32] and has been reported in other tropical settings, where BCG is given at birth [33-35]. It is inconsistent with a published systematic review and meta analysis which reported increased likelihood of a positive TST in BCG vaccinated persons [36]. A weakness of our study, and most others, is reliance on the presence or absence of a BCG scar because of the difficulties in obtaining accurate immunization histories and/or records.

That the TST was not done at the same time as the IGRAs may also be a considered a weakness of this study, as it makes any comparison of IGRA with the TST, subject to mis-classification bias. However, our primary goal was not to compare the IGRAs with the TST but to evaluate the IGRAs in relation to each other. The TST is subject to boosting. Although, there are some reports of possible boosting, by a previous TST, of the QFT-GIT and not the ELISPOT, large conclusive studies are lacking [37-39]. The 1-month time-lag for the overarching study was put in place to minimise any transient boosting effect on $\mathrm{T}$ cell responses. However, it is possible these results could have been affected by test conversion, reversion and boosting.

The higher test failure rate of the ELISPOT, compared to the QFT-GIT, in our study is inconsistent with other studies, where the opposite has been reported [18,21]. We note that we have more stringent criteria for an acceptable test result for ELISPOT than the commercial ELISPOT based test [40]. The spot counting criteria we used are based on our published study where we used mathematical tools to identify a cut-off [12]. Furthermore, the lack of a positive control for QFT-GIT, as mentioned above, may have been a factor.

A limitation of IGRAs is their relatively high cost and need for laboratory infrastructure. The greater through-put of samples for QFT-GIT gives it some advantage in this light. However, one would need to demonstrate significant further advantage over the TST than is seen here, to justify the investment for developing countries in particular. The outstanding question to resolve now is whether IGRAs show improved predictive value for progression to active disease, once an individual is infected with M. tuberculosis. This will require large, possibly multi-site, follow-up studies of TB case contacts and molecular subtyping of case and secondary case isolates. Such follow-up studies are underway in The Gambia.

\section{Conclusion}

This study has shown that an in-house ELISPOT has greater sensitivity than the QFT-GIT for diagnosing active TB disease, and perform similarly with respect to $M$. tuberculosis infection in The Gambia. 
Table 2: Univariable and multivariable odds ratios determined by logistic regression (household as random effect), for sleeping proximity as a surrogate marker of exposure to M. tuberculosis

ESAT-6/CFP-10 ELISPOT $(n=182)$

$$
\text { Positive results }
$$

Positive results
No.(\%) of contacts
Unadjusted $\mathrm{OR}$
$(95 \% \mathrm{Cl})$
Quantiferon $(n=187)$

TST $(n=194) \ldots \ldots .$.

\section{Sleep proximity}

Different house

$$
\begin{gathered}
17 \\
(48.6)
\end{gathered}
$$

I

Adjusted OR P-value

(95\% Cl)

Positive results
No. (\%) of contacts

Unadjusted OR
$(95 \% \mathrm{Cl})$

Positive results

Positive results
No.(\%) of contacts

\section{Different room}

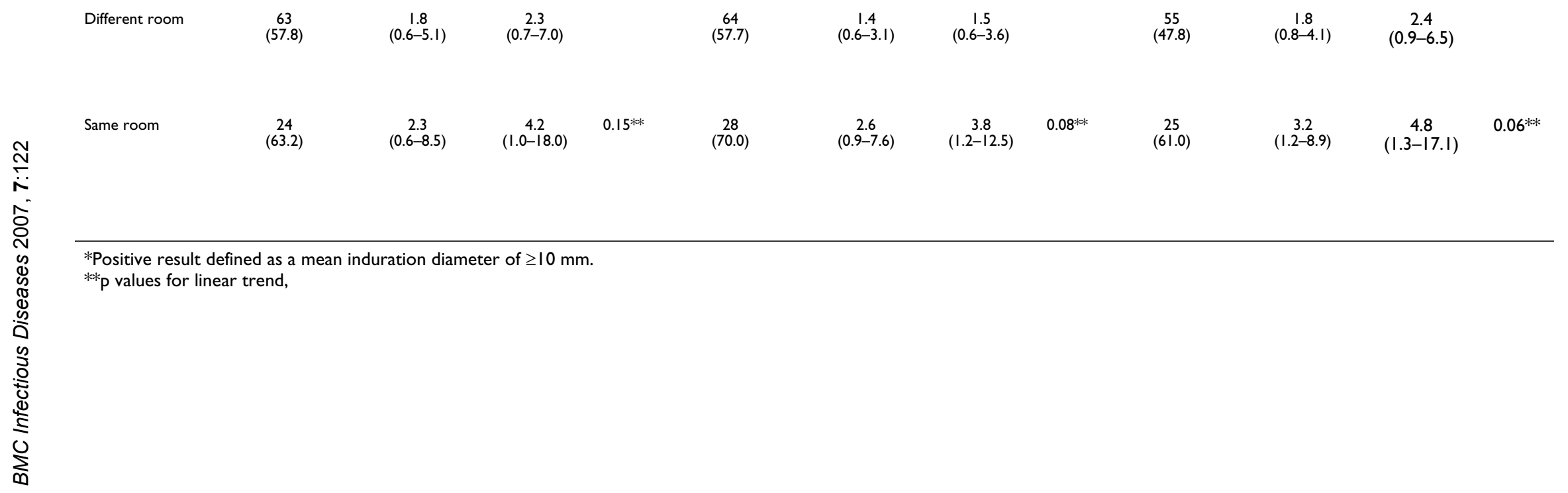

18
$(50.0)$

I

(95\% Cl) 


\section{Competing interests}

The author(s) declare that they have no competing interests.

\section{Authors' contributions}

IMO contributed to study design, conducted field and clinical activities, and was involved interpretation of laboratory data and data analysis.

PC conceived of the study, and participated in its design and coordination, and was involved in data analysis.

DJ contributed to design of the study and data analysis.

SD contributed to study design and managed the data generated.

ML carried out ELISPOTs and was involved in data interpretation.

AH carried out QFT-GIT assays and was involved in data interpretation.

RA provided overall supervision and was responsible for TB diagnostics

All authors read and approved the final manuscript.

\section{Financial support}

This study was funded by the Medical Research Council (United Kingdom), QFT-GIT kits were provided free by Cellestis Limited, Carnegie, Australia. IMOA receives financial support from the European and Developing Countries' Clinical Trials Partnership (EDCTP).

\section{Acknowledgements}

We thank all those who participated in the study, the National Tuberculosis Control Program for their ongoing collaboration, MRC field staff, data room staff, laboratory assistants for their hard work and Dr. Martin Ota for reviewing this manuscript.

\section{References}

I. WHO: Tuberculosis. Fact Sheet No 104, Accessed April 10, 2007 2007 [http://www.who.int/mediacentre/factsheets/fs /04/en/].

2. Pitman R, Jarman B, Coker R: Tuberculosis transmission and the impact of intervention on the incidence of infection. Int $J$ Tuberc Lung Dis 2002, 6:485-49I.

3. Jasmer RM, Nahid P, Hopewell PC: Clinical practice. Latent tuberculosis infection. N Engl J Med 2002, 347: |860-1866.

4. Black GF, Weir RE, Floyd S, Bliss L, Warndorff DK, Crampin AC, Ngwira B, Sichali L, Nazareth B, Blackwell JM, Branson K, Chaguluka SD, Donovan L, Jarman E, King E, Fine PE, Dockrell HM: BCGinduced increase in interferon-gamma response to mycobacterial antigens and efficacy of BCG vaccination in Malawi and the UK: two randomised controlled studies. Lancet 2002, 359:1393-140I.

5. Huebner RE, Schein MF, Bass JB Jr.: The tuberculin skin test. Clin Infect Dis 1993, 17:968-975.

6. Pai M, Riley LW, Colford JM Jr.: Interferon-gamma assays in the immunodiagnosis of tuberculosis: a systematic review. Lancet Infect Dis 2004, 4:76I-776.
7. Menzies D, Pai M, Comstock G: Meta-analysis: new tests for the diagnosis of latent tuberculosis infection: areas of uncertainty and recommendations for research. Ann Intern Med 2007, | 146:340-354.

8. Dinnes J, Deeks J, Kunst H, Gibson A, Cummins E, Waugh N, Drobniewski $F$, Lalvani $A$ : A systematic review of rapid diagnostic tests for the detection of tuberculosis infection. Health Technol Assess 2007, II:I-196.

9. Heifets LB, Good RB: Current laboratory methods for the diagnosis of tuberculosis. In Tuberculosis: protection, pathogenesis, and control Edited by: Bloom BR. Washington, DC, American Society for Microbiology; 1994:85-II0.

10. Adegbola RA, Hill P, Baldeh I, Otu J, Sarr R, Sillah J, Lienhardt C, Corrah T, Manneh K, Drobniewski F, McAdam KP: Surveillance of drug-resistant Mycobacterium tuberculosis in The Gambia. Int J Tuberc Lung Dis 2003, 7:390-393.

II. Lalvani A, Brookes R, Hambleton S, Britton W], Hill AV, McMichael A): Rapid effector function in CD8+ memory T cells. J Exp Med 1997, 186:859-865.

12. Jeffries DJ, Hill PC, Fox A, Lugos M, Jackson-Sillah DJ, Adegbola RA, Brookes RH: Identifying ELISPOT and skin test cut-offs for diagnosis of Mycobacterium tuberculosis infection in The Gambia. Int I Tuberc Lung Dis 2006, 10:192-198.

13. http://www.cellestis.com: QuantiFERON-TB Gold In-Tube: technical information.

14. Lienhardt C, Fielding K, Sillah J, Tunkara A, Donkor S, Manneh K, Warndorff D, McAdam KP, Bennett S: Risk factors for tuberculosis infection in sub-Saharan Africa: a contact study in The Gambia. Am J Respir Crit Care Med 2003, 168:448-455.

15. Hill PC, Brookes RH, Fox A, Fielding K, Jeffries DJ, Jackson-Sillah D, Lugos MD, Owiafe PK, Donkor SA, Hammond AS, Otu JK, Corrah T, Adegbola RA, McAdam KP: Large-scale evaluation of enzymelinked immunospot assay and skin test for diagnosis of Mycobacterium tuberculosis infection against a gradient of exposure in The Gambia. Clin Infect Dis 2004, 38:966-973.

16. Aiken AM, Hill PC, Fox A, McAdam KP, Jackson-Sillah D, Lugos MD, Donkor SA, Adegbola RA, Brookes RH: Reversion of the ELISPOT test after treatment in Gambian tuberculosis cases. BMC Infect Dis 2006, 6:66.

17. Dewan PK, Grinsdale J, Kawamura LM: Low sensitivity of a wholeblood interferon-gamma release assay for detection of active tuberculosis. Clin Infect Dis 2007, 44:69-73.

18. Lee JY, Choi HJ, Park IN, Hong SB, Oh YM, Lim CM, Lee SD, Koh Y, Kim WS, Kim DS, Kim WD, Shim TS: Comparison of two commercial interferon-gamma assays for diagnosing Mycobacterium tuberculosis infection. Eur Respir J 2006, 28:24-30.

19. Tsiouris SJ, Coetzee D, Toro PL, Austin J, Stein Z, El-Sadr W: Sensitivity analysis and potential uses of a novel gamma interferon release assay for diagnosis of tuberculosis. J Clin Microbiol 2006, 44:2844-2850.

20. Goletti D, Carrara S, Vincenti D, Saltini C, Rizzi EB, Schinina V, Ippolito G, Amicosante M, Girardi E: Accuracy of an immune diagnostic assay based on RDI selected epitopes for active tuberculosis in a clinical setting: a pilot study. Clin Microbiol Infect 2006, I 2:544-550.

21. Ferrara G, Losi M, D'Amico R, Roversi P, Piro R, Meacci M, Meccugni B, Dori IM, Andreani A, Bergamini BM, Mussini C, Rumpianesi F, Fabbri LM, Richeldi $L$ : Use in routine clinical practice of two commercial blood tests for diagnosis of infection with Mycobacterium tuberculosis: a prospective study. Lancet 2006, 367:1328-1334.

22. Dogra S, Narang P, Mendiratta DK, Chaturvedi P, Reingold AL, Colford JM Jr., Riley LW, Pai M: Comparison of a whole blood interferon-gamma assay with tuberculin skin testing for the detection of tuberculosis infection in hospitalized children in rural India. J Infect 2007, 54:267-276.

23. Mori T, Sakatani M, Yamagishi F, Takashima T, Kawabe Y, Nagao K Shigeto E, Harada N, Mitarai S, Okada M, Suzuki K, Inoue Y, Tsuyuguchi K, Sasaki Y, Mazurek GH, Tsuyuguchi I: Specific detection of tuberculosis infection: an interferon-gamma-based assay using new antigens. Am J Respir Crit Care Med 2004, 170:59-64.

24. Detjen AK, Keil T, Roll S, Hauer B, Mauch H, Wahn U, Magdorf K: Interferon-gamma release assays improve the diagnosis of tuberculosis and nontuberculous mycobacterial disease in children in a country with a low incidence of tuberculosis. Clin Infect Dis 2007, 45:322-328. 
25. Kang YA, Lee HW, Hwang SS, Um SW, Han SK, Shim YS, Yim J]: Usefulness of Whole-Blood Interferon-\{gamma\} Assay and Interferon-\{gamma\} Enzyme-Linked Immunospot Assay in the Diagnosis of Active Pulmonary Tuberculosis. Chest 2007, I32:959-965.

26. Arend SM, Thijsen SF, Leyten EM, Bouwman JJ, Franken WP, Koster BF, Cobelens FG, van Houte AJ, Bossink AW: Comparison of two interferon-gamma assays and tuberculin skin test for tracing tuberculosis contacts. Am J Respir Crit Care Med 2007, 175:618-627.

27. Harada N, Nakajima Y, Higuchi K, Sekiya Y, Rothel J, Mori T: Screening for tuberculosis infection using whole-blood interferongamma and Mantoux testing among Japanese healthcare workers. Infect Control Hosp Epidemiol 2006, 27:442-448.

28. Diel R, Nienhaus A, Lange $C$, Meywald-Walter K, Forssbohm M, Schaberg $\mathrm{T}$ : Tuberculosis contact investigation with a new, specific blood test in a low-incidence population containing a high proportion of BCG-vaccinated persons. Respir Res 2006, 7:77.

29. Kang YA, Lee HW, Yoon HI, Cho B, Han SK, Shim YS, Yim JJ: Discrepancy between the tuberculin skin test and the wholeblood interferon gamma assay for the diagnosis of latent tuberculosis infection in an intermediate tuberculosis-burden country. Jama 2005, 293:2756-276I.

30. Hill PC, Brookes RH, Fox A, Jackson-Sillah D, Jeffries DJ, Lugos MD, Donkor SA, Adetifa IM, de Jong BC, Aiken AM, Adegbola RA, McAdam KP: Longitudinal Assessment of an ELISPOT Test for Mycobacterium tuberculosis Infection. PLoS Med 2007, 4:e192.

31. Pai M, Menzies D: The new IGRA and the old TST: making good use of disagreement. Am J Respir Crit Care Med 2007, i 75:529-53I.

32. Hill PC, Brookes RH, Adetifa IM, Fox A, Jackson-Sillah D, Lugos MD, Donkor SA, Marshall RJ, Howie SR, Corrah T, Jeffries DJ, Adegbola RA, McAdam KP: Comparison of enzyme-linked immunospot assay and tuberculin skin test in healthy children exposed to Mycobacterium tuberculosis. Pediatrics 2006, I I 7:| 542-I548.

33. Pai M, Gokhale K, Joshi R, Dogra S, Kalantri S, Mendiratta DK, Narang P, Daley CL, Granich RM, Mazurek GH, Reingold AL, Riley LW, Colford JM Jr.: Mycobacterium tuberculosis infection in health care workers in rural India: comparison of a whole-blood interferon gamma assay with tuberculin skin testing. JAMA 2005, 293:2746-2755.

34. Mudido PM, Guwatudde D, Nakakeeto MK, Bukenya GB, Nsamba D, Johnson JL, Mugerwa RD, Ellner JJ, Whalen CC: The effect of bacille Calmette-Guerin vaccination at birth on tuberculin skin test reactivity in Ugandan children. Int J Tuberc Lung Dis | 999, 3:89|-895.

35. Almeida LM, Barbieri MA, Da Paixao AC, Cuevas LE: Use of purified protein derivative to assess the risk of infection in children in close contact with adults with tuberculosis in a population with high Calmette-Guerin bacillus coverage. Pediatr Infect Dis | 2001, 20:1061-1065.

36. Wang L, Turner MO, Elwood RK, Schulzer M, FitzGerald JM: A meta-analysis of the effect of Bacille Calmette Guerin vaccination on tuberculin skin test measurements. Thorax 2002, 57:804-809.

37. Igari H, Watanabe A, Sato T: Booster phenomenon of QuantiFERON-TB Gold after prior intradermal PPD injection. Int J Tuberc Lung Dis 2007, I I:788-791.

38. Leyten EM, Prins C, Bossink AW, Thijsen S, Ottenhoff TH, van Dissel JT, Arend SM: Effect of tuberculin skin testing on a Mycobacterium tuberculosis-specific interferon-gamma assay. Eur Respir 2007, 29:1212-1216.

39. Naseer A, Naqvi S, Kampmann B: Evidence for boosting Mycobacterium tuberculosis-specific IFN-gamma responses at 6 weeks following tuberculin skin testing. Eur Respir J 2007, 29: $1282-1283$

40. Oxford Immunotec: T-SPOT.TB. An aid in the diagnosis of tuberculosis infection. VISUAL PROCEDURE GUIDE. For in vitro diagnostic use. Accessed 2nd May 20072006 [http:www.oxfordimmunotec.com/downloads/Vis ual\%20Procedure\%20Guide\%20(Eng lish).\%20VPTUV4\%20070706.pdf].

\section{Pre-publication history}

The pre-publication history for this paper can be accessed here:

http://www.biomedcentral.com/1471-2334/7/122/pre pub
Publish with Bio Med Central and every scientist can read your work free of charge

"BioMed Central will be the most significant development for disseminating the results of biomedical research in our lifetime. " Sir Paul Nurse, Cancer Research UK

Your research papers will be:

- available free of charge to the entire biomedical community

- peer reviewed and published immediately upon acceptance

- cited in PubMed and archived on PubMed Central

- yours - you keep the copyright

Submit your manuscript here:

http://www.biomedcentral.com/info/publishing_adv.asp
BiolMedcentral 